DOI: $10.2478 /$ lpts-2019-0029

\title{
OPTIMIZATION OF THE SELECTION METHOD FOR RECONSTRUCTION OF OUTWORN GAS DISTRIBUTION PIPELINE
}

\author{
A. Koposovs, I. Bode, L. Zemite, E Dzelzitis, T. Odineca, \\ A. Ansone, A. Selickis, A. Jasevics \\ Riga Technical University, \\ Faculty of Power and Electrical Engineering, Institute of Power Engineering, \\ 12-1 Azenes Str., Riga, LV-1048, LATVIA \\ laila.zemite@rtu.lv
}

\begin{abstract}
Currently, problems related to the operation and exploitation of safe gas distribution networks are deepening in Latvia and Eastern Europe, as the number of outworn underground gas pipelines is steadily increasing. It should be noted that there is a rather wide choice of technology and materials for gas distribution pipeline reconstruction, while at the same time there is no universal method that equally meets all possible work requirements. Therefore, it is an urgent task to understand the operational algorithm, while choosing optimal reconstruction option, classifying and determining the criteria affecting the choice, and determining the scope of each reconstruction method. For this reason, it is necessary to develop a scientifically based methodology for selecting the optimal method for the reconstruction of outworn gas distribution pipelines. Therefore, there are the following tasks that need to be accomplished: to carry out a complex analysis of reconstruction methods and factors determining the choice of an optimal gas distribution pipeline reconstruction method as well as perform the analysis of current state and development of gas supply network; to develop an algorithm for selecting an optimal gas distribution pipeline reconstruction method based on a multi-criteria approach; to develop a mathematical model for the selection of an optimal reconstruction method and scientifically based complex evaluation procedures taking into account technical and economic criteria; to analyse the interaction of the polyethylene gas pipeline with the steel frame during the post-reconstruction process using U-shaped pipe; to develop recommendations for the optimisation of gas distribution network reconstruction programmes. As a result of these tasks, a scientifically justified methodology for the selection of an optimal method for the reconstruction of the gas distribution pipes has been developed.
\end{abstract}

Keywords: gas pipelines, mathematical models, optimization, polyethylene pipes, reconstruction 


\section{INTRODUCTION}

Natural gas distribution systems provide gas transmission to users. The distributing gas pipelines are constructed in urban, village and residential areas. Until 1998, only steel pipes were used to construct gas pipelines, but currently polyethylene tubes are increasingly preferred. Distribution systems include gas regulating equipment, special constructions and pipelines with closing devices, anticorrosive equipment and other network devices. The total length of the distribution system pipelines in Latvia is $5907.69 \mathrm{~km}$ (Table 1).

Table 1

Distribution of Natural Gas Pipeline Construction

\begin{tabular}{|c|c|c|}
\hline \multicolumn{2}{|c|}{ Length of pipelines owned by the company (km) } & $5,243.15$ \\
\hline \multicolumn{2}{|l|}{ High pressure gas pipelines $(\mathrm{km})$} & 997.75 \\
\hline \multicolumn{2}{|l|}{ Medium pressure gas pipelines $(\mathrm{km})$} & $1,848.89$ \\
\hline \multicolumn{2}{|c|}{ Medium pressure gas pipelines $100 \mathrm{mbar}(\mathrm{km})$} & 332.52 \\
\hline \multicolumn{2}{|l|}{ Low pressure gas pipelines $(\mathrm{km})$} & $2,063.98$ \\
\hline \multicolumn{2}{|l|}{ Not owned by the company $(\mathrm{km})$} & 820.01 \\
\hline \multicolumn{2}{|c|}{ Length of pipelines carried out by the company (km) } & $5,907.69$ \\
\hline \multirow{2}{*}{ Owned by gas operator $(\mathrm{km})$} & Steel pipelines & $3,292.64$ \\
\hline & Polyethylene pipelines & $1,950.51$ \\
\hline \multirow{2}{*}{ Not owned by gas operator $(\mathrm{km})$} & Steel pipelines & 203.53 \\
\hline & Polyethylene pipelines & 616.48 \\
\hline
\end{tabular}

The technical operation of the distribution pipeline systems is carried out by the distribution system operator (DSO). The lifetime of the operating steel and polyethylene pipelines is given in Table 2 according to 01.01.2019 data. Certain complex and highly qualified works are carried out by the distribution system operator's special services (e.g., gas pipeline diagnostics, etc.).

Table 2

Lifetime of Operational Steel Pipelines

\begin{tabular}{|c|c|c|c|c|c|c|c|}
\hline \multirow{2}{*}{$\begin{array}{l}\text { Gas pipeline } \\
\text { material }\end{array}$} & \multicolumn{6}{|c|}{ Lifetime of operational pipelines, years } & \multirow[t]{2}{*}{ TOTAL } \\
\hline & below 10 & $10-20$ & $20-30$ & $30-40$ & $40-50$ & above 50 & \\
\hline $\begin{array}{l}\text { Polyethylene, } \\
\text { km }\end{array}$ & 324.24 & 1445.44 & 140.32 & 40.66 & 0.00 & 0.00 & 1950.66 \\
\hline Amount, \% & 17 & 74 & 7 & 2 & 0 & 0 & \\
\hline Steel, km & 30.23 & 244.43 & 729.25 & 985.62 & 846.95 & 456.64 & 3293.12 \\
\hline Amount, \% & 1 & 7 & 22 & 30 & 26 & 14 & \\
\hline TOTAL & 354.47 & 1689.86 & 869.57 & 1026.28 & 846.95 & 456.64 & 5243.78 \\
\hline
\end{tabular}

Results of the analysis of the development phases of Latvian pipeline systems allowed identifying changes in gas distribution network over the past 25 years; it also allowed determining the current state of the network, taking into account the lifetime of pipelines, as well as the level of gasification achieved in the regions and defining the possibilities of using polyethylene pipes and the required gas distribution pipe reconstruction amount. Since the steel pipelines are not constructed in a single 
year, they are operated with a variety of time, depreciation and other factors, which require different technical operations and renovations.

The assessment of the technical state of the natural gas transmission pipeline system $(P>16$ bar) has been studied by A. Borodinecs, A. Broks, A. Dāvis, A. Ješinska, A. Krēsliņš. Natural gas distribution networks $(P<16$ bar $)$ have been studied in the recent years [1]-[6].

\section{METHODOLOGY FOR ASSESSING THE TECHNICAL STATE OF THE PIPELINE AND SETTING THE CONDITIONS FOR FUTURE OPERATIONAL FEASIBILITY}

The methodology for assessing the technical state of the distribution pipeline systems and determining the conditions for future operational feasibility was developed according to the algorithm developed in the study (Fig. 1).

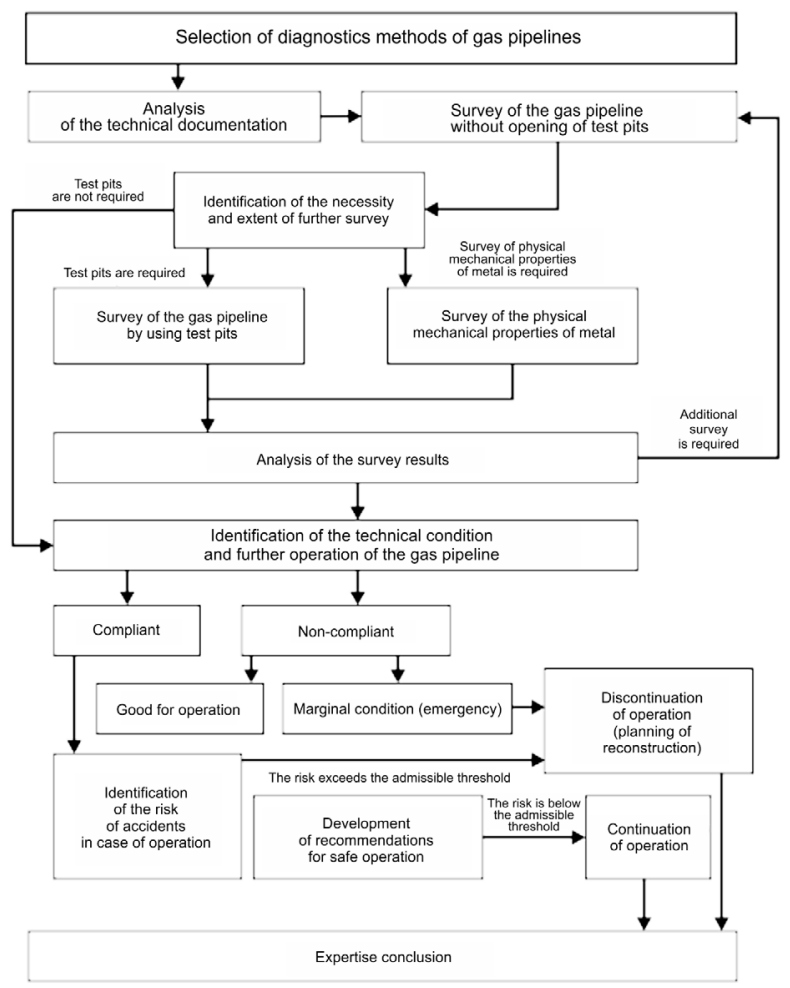

Fig. 1. Algorithm for performing underground steel gas pipeline diagnostics.

In order to assess the technical condition, the possibility of non-accidents in the gas pipeline must be calculated. According to the technical state of the pipeline, the probability of non-accident $-H_{i_{B P}}$ for case $i$ shall be calculated using the following relations based on the results of the technical diagnosis, taking into account the found defects and damage $\left(H_{i_{B P}}\right)$ :

$$
H_{i_{B P}}=\prod_{s_{i}=1}^{s_{i}}\left(1-k_{\Sigma} \cdot P\left(A_{i}\right)\right)^{m s},
$$


where $\Pi-$ multiplication sign of multiplicators, $s_{i}$ - number of defects and types of damage; $k_{\Sigma}$ - correction factor (occurrence of accidents); $P\left(A_{i}\right)$ - probability of occurrence of an accident defect or damage, $m s-$ the number of defects or damage of one type.

After the prevention of any defects and damage $\left(H_{i_{A P}}\right)$ detected during the survey, taking into account defects and damage, which have not been observed for objective and subjective reasons it is possible to calculate:

$$
H_{i_{A P}}=\prod_{s_{i}=1}^{s_{i}}\left(1-k_{\Sigma} \cdot P\left(A_{i}\right)\right)^{L_{s}}
$$

where $L_{s}$ - the number of failures and/or damage, which were not observed.

$k_{\Sigma}$ for the hazards of defects and damage equal to the multiplication of individual factors $k_{i}$ :

$$
k_{\Sigma}=\prod_{i=1}^{n} k_{i}
$$

where $n$ - the amount of correction factors $k_{i}, i$ - the number of individual factor. $L_{s}$ can be calculated using (4):

$$
L_{s}=m s \cdot\left(\frac{\left(1-P_{d-o p}\right.}{P_{d-o p}}\right) \text {, }
$$

where $P_{d-o p}$ is defectoscope operator probability of finding a defect or damage. Probability of occurrence of an accident defect or damage and correction factor (occurrence of accidents) for the hazards of defects and damage is determined on the basis of statistical data on accidents and incidents on gas pipeline, and it is equal to:

$$
P\left(A_{i}\right)=\frac{1}{N \cdot A K_{i}}
$$

where $N \cdot A K_{i}$ - the average occurrence of specific type defects on the gas pipeline per accident, on one kilometre of the pipeline within one year. Correction factors $k_{i}$ can be calculated by (6):

$$
K_{i}=k_{b} \cdot \frac{N_{i}}{N_{\min }},
$$

where $k_{b}$ - the weight factor of the operating conditions, taking into account the varying influence of different impact groups of operation; $N_{i}$ and $N_{\min }-i-$ minimum incidence of defects in one of the operating condition groups.

The correction factor $k_{i}$ for the hazards of defects and damage allows taking into account characteristics of the gas pipeline and operational influence on the hazard level of defects and damage (Table 3). 
Values of the Danger Adjustment Coefficients of Defects and Damage of the Gas Pipeline

\begin{tabular}{|c|c|c|}
\hline \multicolumn{2}{|l|}{ Characteristics of an underground pipeline } & \multirow{2}{*}{$\begin{array}{c}k_{i} \\
\text { (eventual) }\end{array}$} \\
\hline \multicolumn{2}{|l|}{ Operational conditions } & \\
\hline \multirow{3}{*}{ Type } & between the village & 1.00 \\
\hline & distribution & 1.05 \\
\hline & inlet & 1.10 \\
\hline \multirow{3}{*}{ Pressure } & low & 1.00 \\
\hline & medium & 1.05 \\
\hline & high & 1.10 \\
\hline \multirow{4}{*}{$\begin{array}{l}\text { The route of the gas pipeline across natural and } \\
\text { artificial obstacles }\end{array}$} & none & 1.00 \\
\hline & a water obstacle & 1.05 \\
\hline & a road or a railway & 1.10 \\
\hline & a road and a railway & 1.15 \\
\hline \multirow{2}{*}{$\begin{array}{l}\text { Regulated distances from the gas distribution } \\
\text { network }\end{array}$} & complied with & 1.00 \\
\hline & not complied with & 1.05 \\
\hline $\begin{array}{l}\text { The protection potential is ensured along the whole } \\
\text { length or electrical chemical protection, not required }\end{array}$ & & 1.00 \\
\hline $\begin{array}{l}\text { The protection potential is ensured not along the } \\
\text { whole length at a high soil corrosion activity or if } \\
\text { there is a dangerous impact of stray }\end{array}$ & & 1.10 \\
\hline $\begin{array}{l}\text { The protection potential is ensured not along the } \\
\text { whole length at a high soil corrosion activity and if } \\
\text { there is a dangerous impact of stray currents }\end{array}$ & & 1.20 \\
\hline $\begin{array}{l}\text { Interruptions in the operation of the electrical } \\
\text { chemical protection device exceed permitted terms }\end{array}$ & & 1.05 \\
\hline
\end{tabular}

The likelihood of defect is determined:

- based on the characteristics of the used tools and equipment;

- based on the parameters of the gas pipeline;

- based on external factors such as the presence of interference, road surface quality, soil moisture in the area where pipeline lays, etc.;

- based on subjective factors, such as the qualifications of the contractors.

Certain values are determined on the basis of external and subjective factors, but must not exceed the maximum values.

The maximum parameters for the probability of defects and damage are given in Table 4. 
The Maximum Possibility of Identification of Defects and Damage of Gas Pipelines

\begin{tabular}{|l|c|}
\hline \multicolumn{1}{|c|}{ Pescription of the defect section } & $\begin{array}{c}\text { The maximum } \\
\text { possibility of } \\
\text { identification of the } \\
\text { defect }\end{array}$ \\
\hline \multicolumn{1}{|c|}{ Penetrating defect } & 0.98 \\
\hline High pressure & 0.95 \\
\hline Medium pressure & 0.90 \\
\hline Low pressure & 0.85 \\
\hline Low pressure $(d<1 m m)$ & 0.70 \\
\hline \multicolumn{1}{|c|}{ Damage of insulation coating } & 0.75 \\
\hline Within the territory of an inhabited location & 0.80 \\
\hline $\begin{array}{l}\text { Within the territory of inhabited locations where there are no connected } \\
\text { engineering communications }\end{array}$ & 0.98 \\
\hline $\begin{array}{l}\text { Outside an inhabited location } \\
\text { The lack of adhesion along the whole length of a gas pipeline }\end{array}$ & \\
\hline $\begin{array}{l}\text { Destruction of the insulation coating along the whole section (the transitional } \\
\text { resistance below the critical value), as confirmed for several times by means } \\
\text { of test pit surveys }\end{array}$ & 0.99 \\
\hline
\end{tabular}

The values of $P\left(A_{i}\right)$ obtained from the operational statistics of DSO distribution gas pipeline systems are given in Table 5 .

Table 5

The Criteria for Assessing the Degree of Danger of Defects and Damage of the Gas Pipeline

\begin{tabular}{|c|c|c|}
\hline \multicolumn{2}{|c|}{ Defects and damage of the insulation coating } & $P\left(A_{i}\right)$ \\
\hline \multirow{5}{*}{$\begin{array}{l}\text { Mechanical and } \\
\text { structural }\end{array}$} & Damage & 0.0050 \\
\hline & Unsatisfactory adhesion in a test pit & 0.0015 \\
\hline & The lack of adhesion along the whole length of a section & 0.0700 \\
\hline & Transitional resistance in a test pit below the critical value & 0.0030 \\
\hline & $\begin{array}{l}\text { Destruction of the insulation coating along the whole length } \\
\text { of a section }\end{array}$ & 0.0200 \\
\hline \multicolumn{2}{|r|}{ Defects and damage of the pipeline metal } & $P\left(\boldsymbol{A}_{i}\right)$ \\
\hline \multirow{5}{*}{ Corrosion } & Penetrating, $d>1 \mathrm{~mm}$ & 0.250 \\
\hline & Penetrating, $d<1 \mathrm{~mm}$ & 0.1500 \\
\hline & Local (ulcer, point) & 0.0600 \\
\hline & General, the remaining thickness of wall below $70 \%$ & 0.0350 \\
\hline & $\begin{array}{l}\text { General, the remaining thickness of wall between } 99 \% \text { and } \\
\qquad 70 \%\end{array}$ & 0.0200 \\
\hline \multirow{3}{*}{ Structural } & The loss of the pipeline strength & 0.5000 \\
\hline & Rupture of a welded joint & 0.2500 \\
\hline & Defect of a welded joint $d<1 \mathrm{~mm}$ & 0.1500 \\
\hline
\end{tabular}

When determining the number of defects and damage caused by corrosion damage and found in a single viewing area of a size not exceeding $1.5 \mathrm{~m}$, the principle according to which more significant damage covers minor damage should be used. 
For example, if both transverse and point damage are detected in the single viewing area, only the transverse one is taken into account. It is assumed that the number of one type of defect per standard size single viewing area $1.5 \mathrm{~m}$ is 1 .

The assessment of the technical condition is carried out on the basis of the boundary status criterion, the probability of non-accident is equal to 0.95 . Based on the diagnostic results of the gas pipeline, its condition can be evaluated as technically appropriate, operational or boundary. Depending on the probability of non-accident occurrence, developed and recommended time extensions of the safe operating period of the gas pipeline are specified in Table 6.

Table 6

Recommended Extensions of Lifetime

\begin{tabular}{|c|c|}
\hline $\begin{array}{c}\text { The possibility of non-emergence of accidents, } \\
H_{i_{A P}}\end{array}$ & $\begin{array}{c}\text { Recommended term of safe operation, } \\
\text { years, up to }\end{array}$ \\
\hline $0.990-1.000$ & 10 \\
\hline $0.980-0.990$ & 9 \\
\hline $0.975-0.980$ & 8 \\
\hline $0.970-0.975$ & 7 \\
\hline $0.967-0.970$ & 6 \\
\hline $0.964-0.967$ & 5 \\
\hline $0.960-0.964$ & 4 \\
\hline $0.955-0.960$ & 3 \\
\hline $0.950-0.955$ & 2 \\
\hline$\leq 0.950$ & 1 \\
\hline
\end{tabular}

A gas pipeline whose technical condition is recognised as a boundary state $\left(H_{i_{A P}}<0.950\right)$ must be decommissioned, reconstruction or refurbishment of the pipeline must be carried out. A gas pipeline whose condition is recognised as operational $\left(H_{i_{A P}}<0.950\right)$ is considered fit for operation if safe operation measures are implemented. If, despite the detection of defects, according to diagnostic results and calculations, probability of non-accident until their elimination exceeds 0.950 and the gas pipeline can be declared operational, these defects shall be considered as repairable.

From the economic indicator aspect, the dominant method of reconstruction is the one where polyethylene pipes are laid in without degrading the steel pipeline. In addition, the impact of the territorial area of construction indicator, takes into account the density and nature of the buildings in areas where gas pipes are laid.

Advantages of the reconstruction method with pipe laying without predegradation are the following: simplicity of construction works; cheapness of technology; the possibility of using standard polyethylene pipes and coupling parts; complete refusal of electrochemical protection installation. Disadvantages are limits of strength reserve coefficient; difficult gas leak detection; significant reduction in flow and relatively low load-bearing capacity. Advantages of the reconstruction method with pipe laying with pre-degradation are the following: the possibility of replacing the pipes with the same or greater diameter pipes; there is no need to clean the pipeline before; with polyethylene pipes, the reconstructed section does not require standard polyethylene pipes. Disadvantages are that it is necessary to 
make reinforced pipes; significant constraints in the case of engineering networks, expenditure related to the Environmental Impact Assessment; small length of reconstructed pipeline sections and pipe curves make work difficult. Advantages of reconstructing a tightly sealed pipe (U-type) are the following: minimal reduction in pipeline diameter; permeability is not limited; no need for standard polyethylene pipes in reconstructed pipeline. Minuses are that careful inspection and cleaning of the old pipelines are needed; additional equipment for special pipe handling and trained personnel is required; pipe diameter and pressure limits and refitting are necessary. Advantages of the reconstruction by using synthetic pipe branch are the following: minimum equipment required; it is possible to reconstruct long pipelines; the possibility to reconstruct the gas pipelines at a pressure of up to $1.2 \mathrm{MPa}$. Disadvantages are that it is possible to break the pipe branch in the reconstruction process; after the reconstruction, the steel pipeline may require protection using standard polyethylene pipes; relatively expensive technology; careful cleaning of the old pipe needs to be done. Advantages of "primus line" [6] method are high permissible load; high flexibility; high efficiency; non-significant impact on landscape and protected areas; possibility to perform recovery of long pipelines with sharp turns. Disadvantages are high costs of the technology; there are not many large-scale entrepreneurs who could implement this type of technology and due to the inaccuracy of the tractive force calculation, it is possible to break the pipe branch during the laying process. Advantages of the open reconstruction method are that there are no temperature or other limits for the performance of works; a potential increase in pressure in a new city where an increase in gas consumption is likely to occur. Disadvantages are high costs of the technology; high environmental pollution; long duration of work; disruption of transport movement at work site.

The analysis of the existing European legislation confirmed the need to take this indicator into account in the process of choosing the optimal gas distribution pipeline reconstruction option, as the task associated with optimum reconstruction is linked to many factors. This task should be based on high-quality engineering research and diagnostic research data, safety requirements and evaluation of existing regulatory framework [7]-[10].

\section{ALGORITHM FOR SELECTING RECONSTRUCTION METHOD FOR OUTWORN GAS DISTRIBUTION PIPELINES}

As a result of the above-mentioned research and methods, the algorithm and methodology for choosing the optimal method for the reconstruction of the outworn gas distribution pipes have been developed (Fig. 2), based on a multi-criteria approach.

The methodology developed is implemented in the following phases: collecting information - identification of feasible solutions - appointing experts and expert groups - determination of comparison criteria - identifying questions and drawing up questionnaires - analysis of expert assessments - determination of competence coefficients - multi-factor analysis mathematical model calculation comparing alternatives - choice of optimal method. The study, on the choice of an 
optimal reconstruction method, proposes an approach based on two sets of criteria: technical and economic. The following criteria have been adopted using analysis as well as technical documentation, with the greatest impact on the selection of an optimal reconstruction option (Table 7).

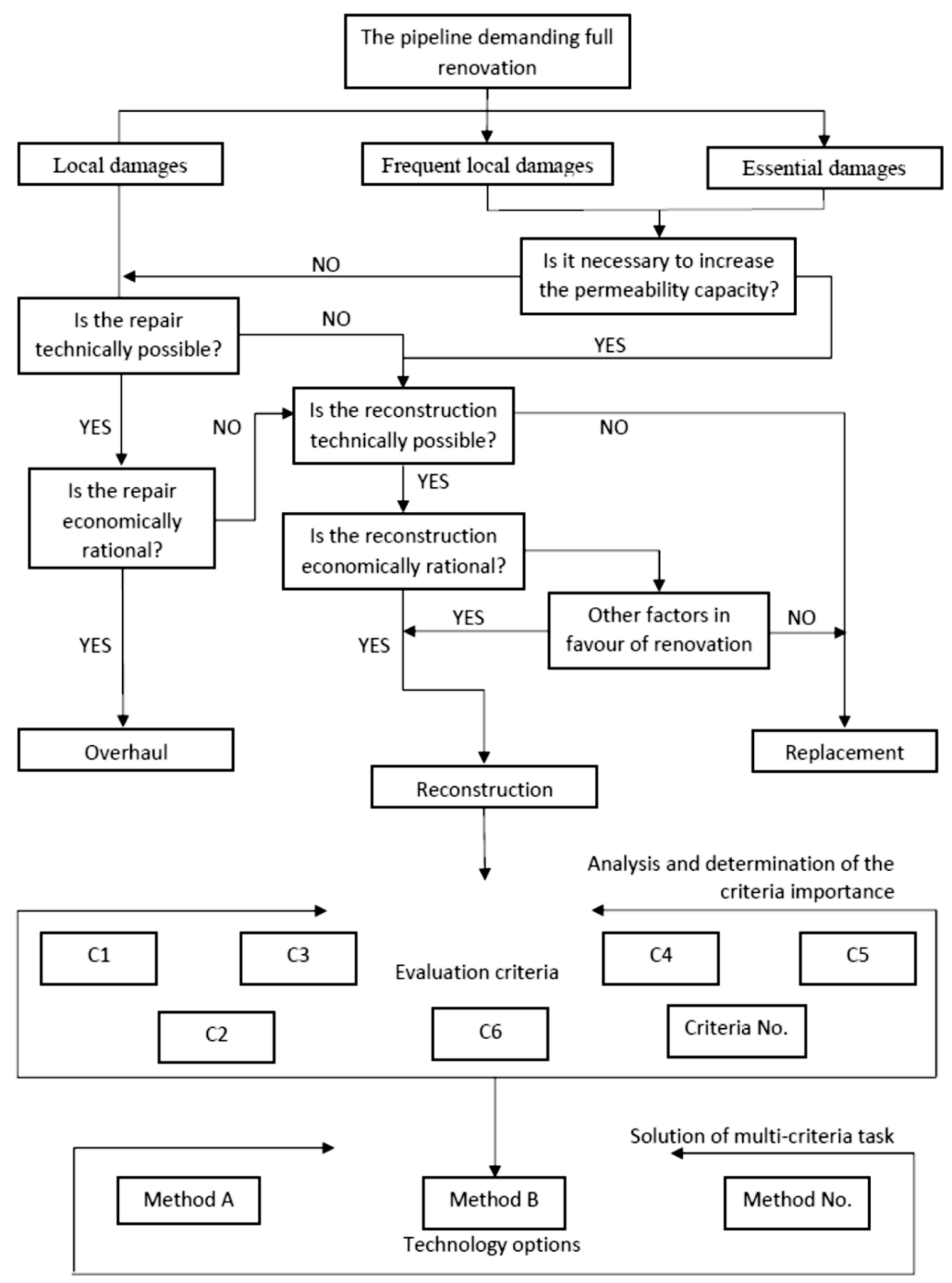

Fig. 2. Algorithm for choosing the optimal reconstruction method.

Based on criteria and the expert analysis questionnaire, assessment and data collection were done in order to create a mathematical model. Taking into account specific calculated competence coefficients and factor importance coefficients, a group calculation was performed for each reconstruction method. The results and calculations of engineers in the program complex Expert Choice indicated that reconstruction for outworn gas distribution pipe, by using a method with tightly attached pipe, might be considered optimal when assessed from the perspective of technical criteria. 
Criteria for Assessment

\begin{tabular}{|l|c|}
\hline \multicolumn{1}{|c|}{ Temparison criteria } & Symbol \\
\hline \multicolumn{2}{|c|}{ Techical criteria } \\
\hline $\begin{array}{l}\text { Gas pipeline operating pressure } \\
\text { Degree of preparedness of reconstructed gas pipeline (volume of works and extent of } \\
\text { larifation of internal space) }\end{array}$ & $\mathrm{C} 1$ \\
\hline Volume of earthwork & $\mathrm{C} 2$ \\
\hline Diameter of reconstructed gas pipeline & $\mathrm{C} 3$ \\
\hline Frequency of occurrence of emergency situations in case of the relevant method & $\mathrm{C} 4$ \\
\hline Level of restrictions of the transport movement intensity & $\mathrm{C} 5$ \\
\hline Necessity of electrochemical protection & $\mathrm{C} 6$ \\
\hline Land allocation area for the period of construction and assembly work & $\mathrm{C} 7$ \\
\hline Degree of complexity of quality control & $\mathrm{C} 8$ \\
\hline Possibility of use of the standard equipment & $\mathrm{C} 9$ \\
\hline Territorial area of work & $\mathrm{C} 10$ \\
\hline Permissible length of the reconstructed gas pipeline stage & $\mathrm{C} 11$ \\
\hline Economic criteria & $\mathrm{C} 12$ \\
\hline Construction costs & \\
\hline Internal rate of return & $\mathrm{C} 13$ \\
\hline Net discounted profit & $\mathrm{C} 14$ \\
\hline Profit index & $\mathrm{C} 15$ \\
\hline Repayment duration & $\mathrm{C} 16$ \\
\hline Duration of construction and assembly work & $\mathrm{C} 17$ \\
\hline
\end{tabular}

\section{OPTIMAL SEQUENCE OF RECONSTRUCTION PROJECT IMPLEMENTATION}

Applying the optimal sequence of implementation of reconstruction projects allows determining the order in which reconstruction should be done, taking into account the technical condition and financial constraints of the distribution network stations. To determine the degree of depreciation and the technical condition of the gas distribution pipelines, it is proposed to perform the planned reconstruction in the following stages: functional diagnostics and risk analysis of complex technical diagnostics. According to the results of functional diagnosis, the technical condition of the gas distribution system object may be recognised as:

- $\quad$ valid for work; condition of the site is described as free of defects and damage that affects the bearing capacity and operational validity;

- valid for work; condition in which several assessable parameters do not comply with the requirements or norms of the project, but this noncompliance with the requirements does not lead to working disruption and the bearing capacity of construction is ensured, taking into account the effects of existing defects and damage;

- inoperable; the condition of the object, in which characterising ability of at least one parameter, to perform the specified functions, does not meet the regulatory technical and/or project requirements. 
If an object is found to be inoperable or if hidden defects are detected during functional diagnosis, it is necessary to perform a complex technical diagnosis of the site. A summary of implementation of the technical status assessment and reconstruction projects is proposed based on a comparison of the risk indicators with an acceptable risk. In order to carry out an overall risk assessment of gas distribution network objects, it is proposed to confirm the expected loss due to the accident, determining the amount of specific losses in monetary terms, which is not limited only to a qualitative risk analysis. Optimal allocation of funds through the implementation of the reconstruction program is an important task of reconstruction of objects because it allows providing a certain financial effect in the circumstances where financial constraints are imposed. The solution for the specific task is proposed by using the dynamic programming method.

\section{CONCLUSIONS}

Studies of existing methods for the reconstruction of outworn gas pipelines have allowed identifying and systemising the main advantages and disadvantages of each method, as well as identifying criteria that influence an optimal selection of the method. It should be noted that the task of selecting an optimal reconstruction method is a multi-factor one. The developed concept allows determining the optimal method of reconstruction of gas distribution pipeline taking into account technical and economic criteria. Technical feasibility has been demonstrated for the use of polyethylene pipes in the reconstruction of gas pipes designed for 1.2 MPa operation together with a steel frame, the role of which is fulfilled by a renewable steel gas pipeline. The developed recommendations and algorithm allow determining an optimal sequence for the implementation of reconstruction projects taking into account both the technical state of the pipelines and the financial constraints.

\section{ACKNOWLEDGMENTS}

The research has been supported by the National Research Programme, project: Trends, Challenges and Solutions of Latvian Gas Infrastructure Development (LAGAS) (No. VPP-EM-INFRA-2018/1-0003).

\section{REFERENCES}

1. Bode, I., Laube, I., \& Platais, I. (2013). Technical Condition. Assessment of the System of Gas Distribution Pipelines. Scientific Journal of RTU. 14 series, Būvzinātne, $6 \mathrm{p}$.

2. Bode, I. (2014). Sadales gāzesvadu sistēmu tehniskā stāvokḷa novērtēšanas metodologiija. Promocijas darbs. R.: RTU Izdevniecība.

3. Zemīte, L., Kutjuns, A., Bode, I., Kuṇickis, M., \& Zeltiņš, N. (2018). Risk treatment and system recovery analysis of gas system of gas and electricity network of Latvia. Latvian Journal of Physics and Technical Sciences, 55(5), 3-14. ISSN 0868-8257. DOI: 10.2478/ lpts-2018-0031 
4. Zemīte, L., Kutjuns, A., Bode, I., Kuņickis, M., \& Zeltiņš, N. (2018). Consistency analysis and data consultation of gas system of gas-electricity network of Latvia. Latvian Journal of Physics and Technical Sciences, 55(1), 22-34. ISSN 0868-8257. DOI:10.2478/lpts2018-0003

5. Zemite, L., Bode, I., Zeltins, N., Kutjuns, A., \& Zbanovs, A. (2018). Analysis of the power system damage hazard from the point of view of the gas supply system. In: 2018 IEEE International Conference on Environment and Electrical Engineering and IEEE Industrial and Commercial Power Systems Europe, EEEIC/I and CPS Europe 2018, art. no. 8494380. ISBN: 978-153865185-8, DOI: 10.1109/EEEIC.2018.8494380

6. Primusline. (n.d.) Available at https://www.primusline.com/primus-line/

7. Praks, P., Kopustinskas, V., \& Masera, M. (2015). Probabilistic modelling of security of supply in gas networks and evaluation of new infrastructure. Reliability Engineering and System Safety, 144, 254-264, DOI: 10.1016/j.ress.2015.08.005

8. Ministry of Economics of the Republic of Latvia. (n.d.). Doing business evaluation of national gas markets, report for regional gas market coordination group.

9. Chala, G.T., Aziz, A.R.A., \& Hagos, F.Y. (2018). Natural gas engine technologies: challenges and energy sustainability issue. Energies, 11(11), art. no. en11112934. DOI: 10.3390/en11112934

10. Miedema, J.H., Van Der Windt, H.J., \& Moll, H.C. (2018). Opportunities and barriers for biomass gasification for green gas in the dutch residential sector. Energies, 11(11), art. no. en11112969. DOI: 10.3390/en11112969

\section{NOLIETOTU GĀZES SADALES VADU ATJAUNOŠANAS METODES IZVĒLES OPTIMIZĀCIJA}

A.Koposovs, I. Bode, L. Zemīte, E Dzelzītis, T. Odiņeca, A.Ansone, A.Selickis, A.Jasevičs

Kopsavilkums

Rakstā apskatīta zinātniski pamatota optimālas nolietotu gāzes sadales vadu rekonstrukcijas metodes izvēles metodika, balstīta uz multi-kritēriju pieeju, un dotas rekomendācijas gāzes sadales tīkla rekonstrukcijas programmu optimizācijai. Tās var risināt problēmas, kas saistītas ar drošas gāzes sadales tīklu darbības un ekspluatācijas nodrošināšanu, jo Latvijā pastāvīgi palielinās nolietoto pazemes gāzes vadu skaits.

05.08.2019. 